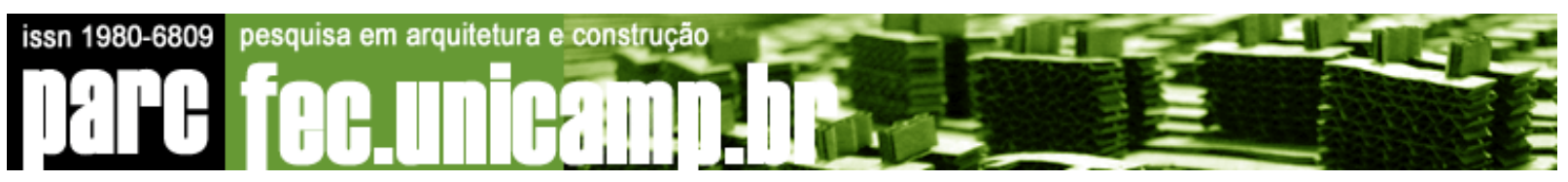

\title{
Utilização de ambiente virtual de aprendizagem em disciplinas de projeto arquitetônico
}

\author{
Use of virtual learning environment in architectural design courses
}

\section{LUISA RODRIGUES FÉLIX DALLA VECCHIA}

ALICE THERESINHA CYBIS PEREIRA

1. Graduada em Arquitetura e Urbanismo pela Universidade Federal de Pelotas, mestre pelo Programa de Pós- Graduação em Arquitetura e Urbanismo da Universidade Federal de Santa Catarina.

2. PhD pela Universidade de Sheffield/UK, professora do Departamento de Expressão Gráfica da Universidade Federal de Santa Catarina.

isa_luls@hotmail.com

acybis@gmail.com

\section{Resumo}

Esta pesquisa tem o objetivo de identificar formas de inserção, no ensino de projeto arquitetônico, de recursos tecnológicos disponíveis em Ambientes Virtuais de Aprendizagem e na computação gráfica. Para se alcançar os objetivos estudaram-se referenciais relativos ao desenvolvimento e ensino de projeto arquitetônico e sua representação. Também foi realizado um experimento em que o Ambiente Virtual de Aprendizagem em Arquitetura e Design foi usado em uma disciplina de projeto arquitetônico do curso de graduação em Arquitetura e Urbanismo da Universidade Federal de Santa Catarina. Busca-se apontar pontos positivos e negativos para a inserção dos recursos tecnológicos de AVAs no ensino de Projeto Arquitetônico com o objetivo de melhorar o ambiente virtual em estudo para este fim tendo em vista o uso intenso da linguagem gráfico-visual usada nestas disciplinas.

Palavras-chave: Ambiente virtual de aprendizagem; projeto arquitetônico; computação gráfica.

\section{Abstract}

This research intends to identify ways of inserting technological resources available in Virtual Learning Environments in the process of learning architectural design. To reach the objectives references regarding the development and the learning process of architectural design were studied and an experiment was carried out in which the virtual learning environment on architecture and design was used with a class of students on architectural design with the intention of pointing out positive and negative aspects of the insertion of technological resources from the virtual learning environments in architectural design courses in order to improve the environment for this use considering the intense use of the visual-graphic language used in this context.

Keywords: Virtual Learning Environments; architectural design; computer graphics 


\section{Utilização de ambiente virtual de aprendizagem em disciplinas de projeto arquitetônico}

\section{Introdução}

Este trabalho tem o objetivo de analisar e testar o ambiente virtual de aprendizagem AVA-AD (Ambientes Virtuais de Aprendizagem em Arquitetura e Design) no ensino/aprendizagem de Projeto Arquitetônico, dando suporte presencial e à distância. Busca-se identificar recursos gráficos digitais apropriados para o desenvolvimento do projeto arquitetônico e possíveis de serem utilizados no ensino de projeto através de tecnologias de informação e comunicação, considerando a possibilidade oferecida por estas tecnologias de ampliar o tempo e o espaço disponível para o estabelecimento de momentos colaborativos entre professor/aluno e aluno/aluno tradicionalmente desenvolvidos em situações presenciais. Considera-se que existam recursos disponíveis capazes de sustentar atividades do projeto arquitetônico, que possam ser usados em ambiente virtual de aprendizagem. $\mathrm{O}$ trabalho foi dividido em duas etapas principais. A primeira etapa é referente ao estudo de trabalhos de referência e a segunda, que se destaca como a etapa principal, diz respeito ao teste de uso do AVA-AD com uma turma de estudantes de projeto arquitetônico.

O projeto AVA-AD vem sendo desenvolvido desde 2001 no Laboratório de Ambientes Virtuais de Aprendizagem (Hiperlab), do Departamento de Expressão Gráfica, da Universidade Federal de Santa Catarina com o apoio do CNPq e tem o objetivo de estruturar ambientes virtuais de aprendizagem específicos para arquitetura e design, ou seja, áreas que utilizam a linguagem gráfico-visual, em termos pedagógicos e tecnológicos (GONÇALVES e PEREIRA, 2005), bem como "aprofundar conceitos aplicados às áreas de Arquitetura e Design, explorando-os de forma interativa, colaborativa e flexível, considerando o potencial das Tecnologias da Informação e Comunicação na aprendizagem à distância" (PEREIRA, 2007).

O AVA-AD está baseado no sistema Moodle que, segundo o site http:/ /moodle.org/, é um CMS (course management system) ou sistema de gerenciamento de curso, gratuito e de código aberto (open source) desenvolvido para ajudar educadores a criar comunidades de aprendizagem online.

O AVA-AD está estruturado a partir de cinco eixos no que diz respeito às estratégias de aprendizagem, aos recursos e ferramentas tecnológicas e as possibilidades de interação e 
comunicação: (1) Eixo de coordenação - apresenta ferramentas que subsidiam e organizam as ações do grupo de usuários bem como ferramentas que apóiam o coordenador no gerenciamento de cursos; (2) Eixo de documentação - dispõe de banco de imagens, banco de textos, material didático, vídeos, animações, apresentações, galeria com trabalhos já desenvolvidos pelos grupos, permitindo que o aprendiz realize consultas em qualquer momento; (3) Eixo de produção - evidencia a participação ativa e interativa do aprendiz, neste eixo são disponibilizados os problemas, baseados em casos reais, que objetivam integrar a teoria e prática dos conteúdos aplicados à Arquitetura e ao Design; (4) Eixo de informação neste eixo estão organizados materiais com informações sistematizadas pelo professor, assim como os materiais de apoio à resolução de problemas e às atividades colaborativas; (5) Eixo de comunicação - reúne ferramentas que dão suporte às atividades desenvolvidas pelos aprendizes no AVA-AD. Assim, as ferramentas de email, chat e fórum estão disponíveis para diálogos e interações entre aprendizes/aprendizes, tutores/aprendizes, professores/aprendizes e apresentam a possibilidade de anexar imagens. Destaca-se que o ambiente colaborativo 2D e 3D inclui área de chat e área gráfica, onde os aspectos gráficos e cromáticos dos projetos podem ser visualizados e analisados em grupo de forma síncrona ou assíncrona. (PEREIRA, 2007).

Referente ao ensino de projeto arquitetônico Schön (2000) afirma que este processo se estabelece principalmente através de ateliês em que se aprende fazendo, ele coloca que, para muitos estudantes de arquitetura, o processo de projeto é bastante confuso e que muitos consideram misteriosa a experiência do ateliê como um todo.

Já Del Rio (1998) considera dois modelos possíveis, um intuitivo e outro racional, porém coloca que eles não são excludentes. Segundo Del Rio (1998) o modelo racional considera a arquitetura como mais próximo das ciências sociais aplicadas do que da arte pura, ele diz que neste modelo racional a criatividade possui maiores chances de expressarse do que no método intuitivo tradicional, pois é direcionada através de procedimentos lógicos em um 'caminho' de projeto.

Segundo Schlemmer (2005) o uso das tecnologias de informação e comunicação (TIC), principalmente a internet, "vem revolucionando as formas de ensinar e aprender", uma maneira de utilizar as TICs para o ensino é através de ambientes virtuais de aprendizagem. Neste sentido o uso de um ambiente virtual de aprendizagem para dar apoio a disciplinas de projeto arquitetônico poderia auxiliar no estabelecimento deste modelo racional à medida que o processo de ensino e do próprio desenvolvimento do projeto do estudante são registrados e 


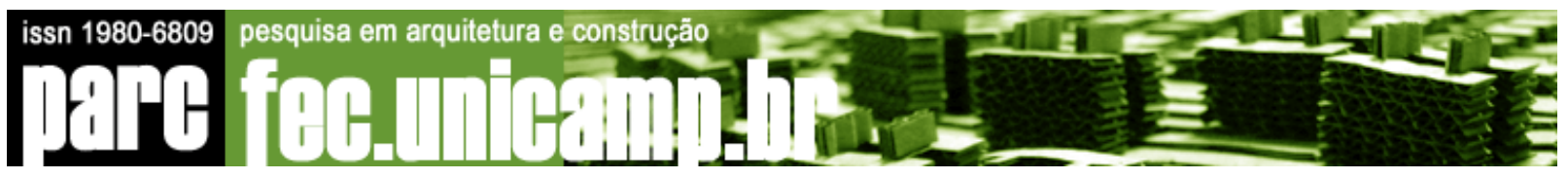

podem ser retomados a qualquer momento além de facilitar a comunicação e acesso as informações do semestre por parte dos estudantes.

\section{Experimentação}

A proposta do experimento foi testar o AVA-AD com uma turma de estudantes de arquitetura da na disciplina de Projeto Arquitetônico III. O objetivo buscado foi identificar situações positivas e negativas deste ambiente para dar apoio a disciplinas de projeto arquitetônico e ainda identificar maneiras de usar a computação gráfica através do ambiente virtual de aprendizagem.

\section{A disciplina de Projeto Arquitetônico III}

O objetivo principal desta disciplina é desenvolver projetos de aprendizagem que estimulem as habilidades cognitivas do estudante, capacitando-o ao exercício do projeto arquitetônico de espaços públicos, como elemento configurador de centralidades urbanas. A experimentação para este projeto foi desenvolvida com a turma do primeiro semestre de 2007, composta de 13 estudantes.

A disciplina foi dividida em três etapas principais: a primeira referente ao Concurso de Idéias, a segunda de definição do Partido Geral e a terceira de Anteprojeto. Na primeira etapa foi introduzido o objeto de estudo e feita a identificação das problemáticas das centralidades urbanas e uso dos espaços públicos. Nesta etapa a turma foi dividida em quatro grupos, cada grupo escolheu uma área para o futuro desenvolvimento do projeto e desenvolveu uma proposta de tema para o projeto naquela área. Ao final desta etapa foi eleita pelos estudantes, uma área para ser desenvolvido o trabalho e uma proposta de tema, que a turma inteira usaria para o desenvolvimento do projeto.

$\mathrm{Na}$ segunda etapa foi feita a formulação conceitual da proposta arquitetônica e o desenvolvimento do plano urbanístico geral para a organização do espaço público na centralidade urbana selecionada na etapa anterior, para esta etapa a turma foi dividida em três grupos. Inicialmente cada grupo desenvolveu uma atividade diferente, um grupo fez uma maquete analógica do terreno e seu entorno, outro gerou uma maquete digital e o outro desenvolveu a planta digital do terreno no entorno. Em seguida cada grupo formulou uma proposta relacionando o espaço escolhido com o entorno, incluindo um estudo da volumetria para o local. 


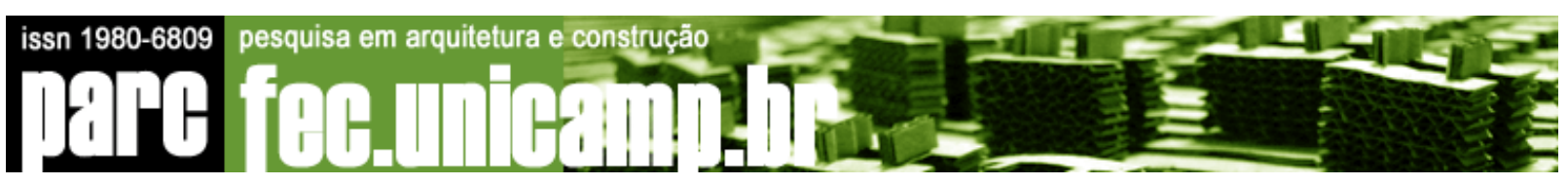

$\mathrm{Na}$ terceira etapa foi feito o desenvolvimento e detalhamento do anteprojeto de forma individual.

\section{O uso do AVA-AD na disciplina de Projeto Arquitetônico III}

O uso do AVA-AD na disciplina buscou explorar ferramentas disponíveis no ambiente em função de cada uma das atividades propostas nas diferentes etapas. Dentre as ferramentas presentes no AVA-AD destacam-se: Bate-Papo, Correio eletrônico, Fóruns, Mensagens Instantâneas, Quadro Branco Compartilhado (ambiente colaborativo 2D), Navegação VRML Compartilhada (ambiente colaborativo 3D), Editor de Texto Compartilhado, Compartilhamento de Documentos, Registro de Novos usuários e Criação de Grupos, Agenda Compartilhada. É importante destacar que não era obrigatório o uso do AVA-AD por parte dos estudantes.

Quanto ao uso do AVA-AD na primeira etapa, inicialmente foram abertos dois fóruns de discussão, um que pretendia ser usado ao longo de todo o semestre, para esclarecer dúvidas sobre o uso do ambiente (FIG. 1), e o outro sobre conceito e método de projeto em que os alunos falavam sobre os outros projetos que haviam desenvolvido buscando identificar os métodos e conceito.

Com relação à utilização do fórum sobre o uso do ambiente destaca-se que $23 \%$ dos estudantes (três estudantes) postaram neste fórum e observa-se que mesmo quem não postou mensagens neste fórum pode ter esclarecido dúvidas apenas lendo o que outros já haviam perguntado, pois 85\% dos estudantes (onze estudantes) visualizaram este fórum. Com relação à utilização do fórum sobre conceito e método de projeto observa-se que $62 \%$ dos estudantes (oito estudantes) postaram mensagens analisando seus projetos. 

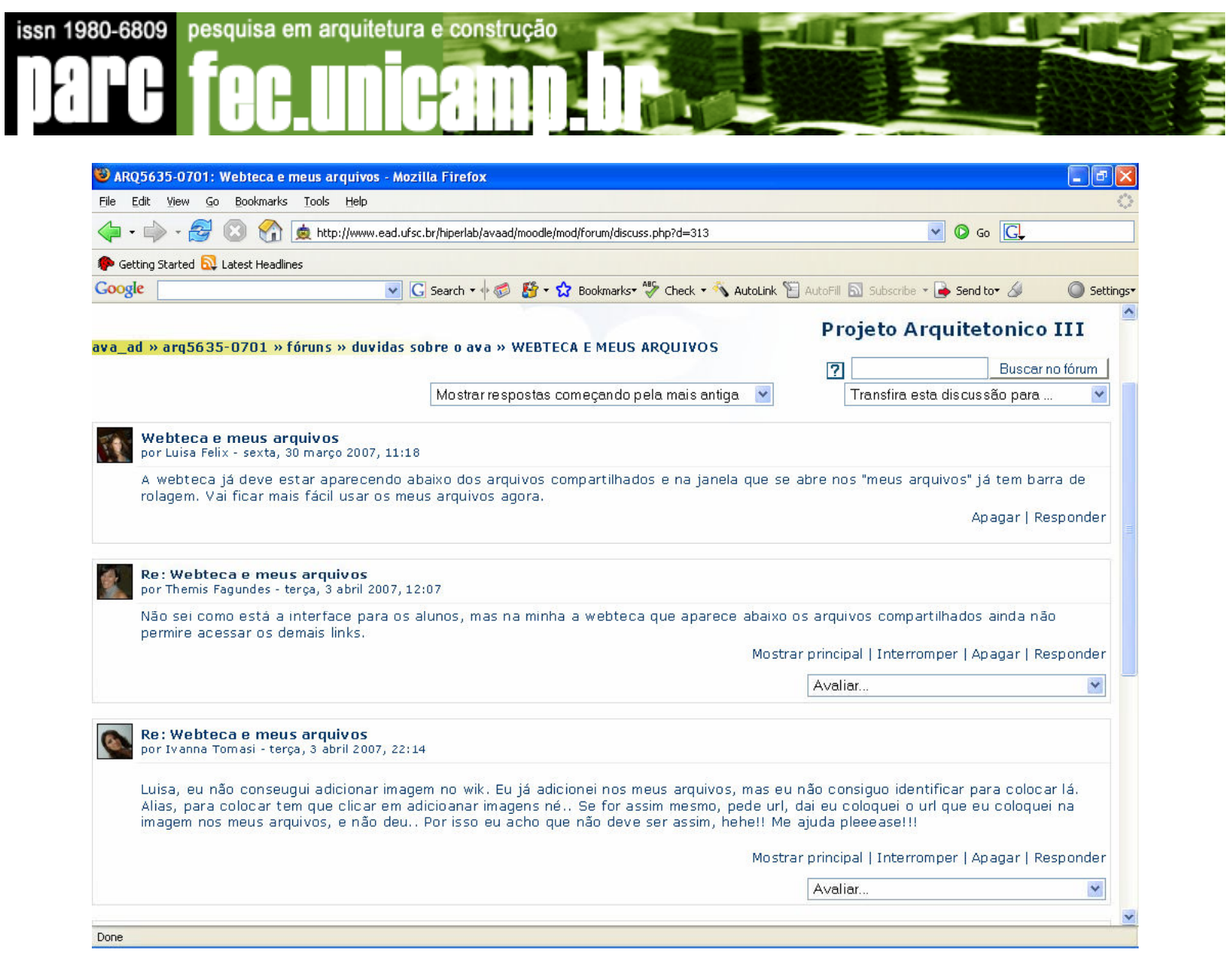

FIGURA 1: Exemplo da interface de Fórum de discussão.

Para o desenvolvimento do concurso de idéias foi aberta uma atividade de wiki (editor de texto compartilhado) em que cada grupo desenvolveu sua idéia do local e tema, a interface de edição de wiki está demonstrada na FIG. 2.

Quanto ao uso pelos estudantes do texto compartilhado destaca-se que embora 100\% dos grupos (três grupos) tenham feito uso da ferramenta, apenas 67\% (dois grupos) desenvolveram sua proposta para o concurso de idéias utilizando esta ferramenta. 


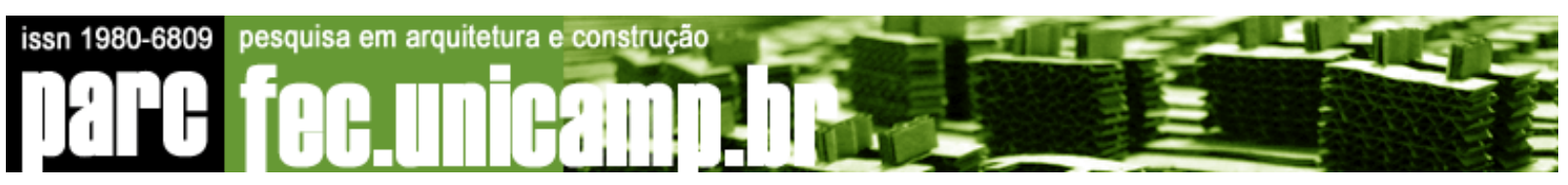

ava_ad " arq5635-0701 " wikis " concurso de idéias " ATIVIDADE 1

Projeto Arquitetonico III

Grupos Wiki para grupoCristina:

Buscar: - EscolherWikiLinks -

\begin{tabular}{|lr|}
\multicolumn{1}{l}{} & \multicolumn{2}{c|}{ Atualizar Wiki } \\
\cline { 3 - 3 } Outros Wikis: & Escolher... \\
\hline -Administraçã̃o-- & ฯ \\
\hline
\end{tabular}

\section{Editar esta página 'a tividade 1'}

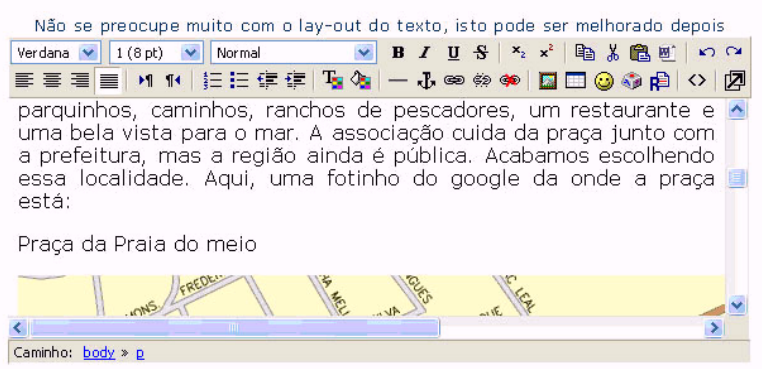

Salvar Ver esboço Cancelar

FIGURA 2: Exemplo da interface de edição de wiki.

Ao final do prazo para o desenvolvimento dessa primeira etapa todos os alunos analisaram as propostas de todos os grupos. No AVA-AD foi criado um fórum para a discussão das diferentes propostas e foram abertas duas pesquisas de opinião, uma para ser votada a área para desenvolvimento do projeto e outra o tema do projeto a ser desenvolvido durante o semestre. A FIG. 3 mostra a interface de visualização dos resultados.

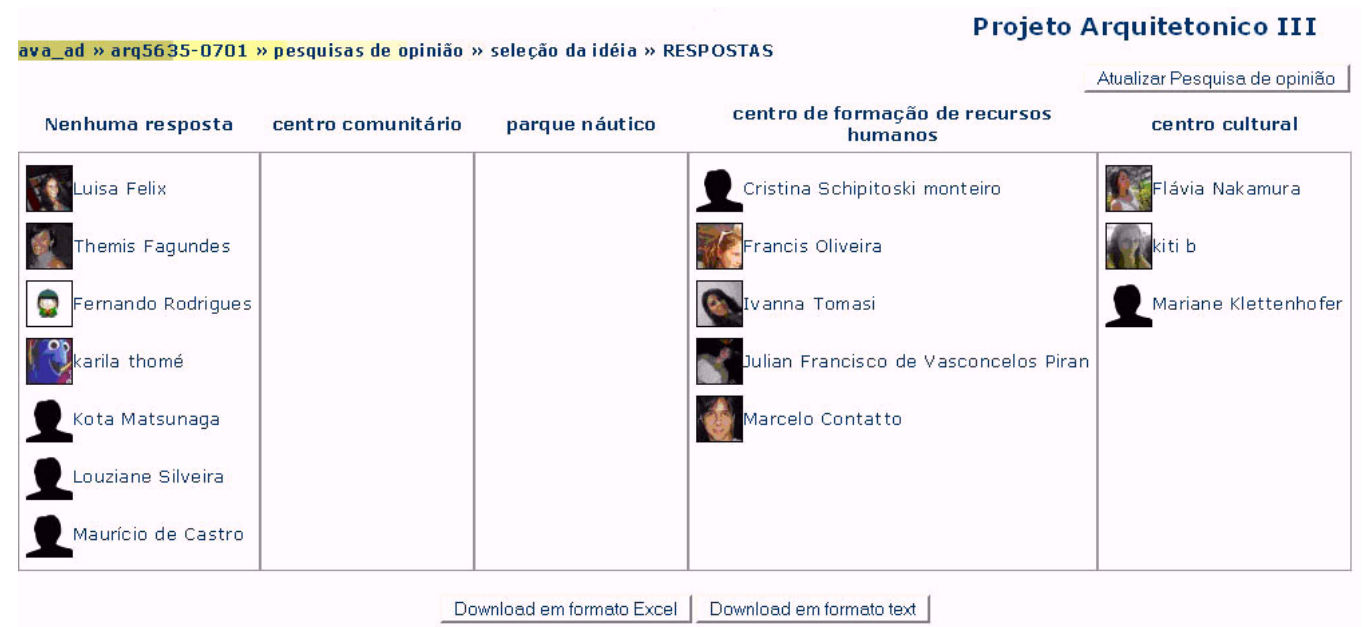

FIGURA 3: Visualização de resultados da pesquisa de opinião

Para a segunda etapa o material digital produzido pelos grupos foi disponibilizado no AVA-AD. A partir da maquete digital da volumetria do entorno do terreno foi gerado um arquivo VRML para ficar disponível no ambiente colaborativo 3D (Navegação VRML Compartilhada) do AVA-AD, para a visualização da volumetria do entorno, este ambiente 


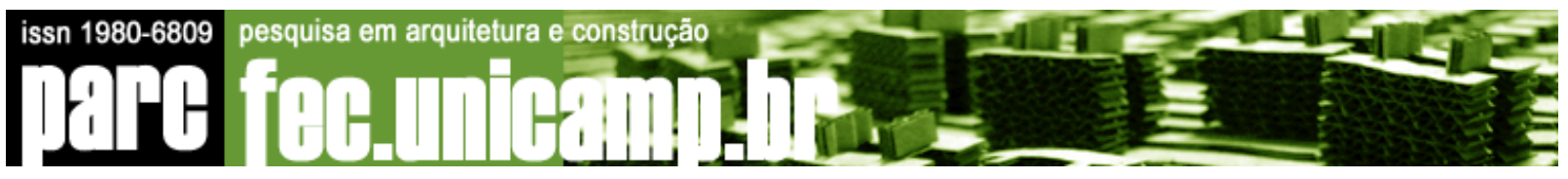

utiliza o software Mediaplataform. A partir da planta digital foram geradas imagens que ficaram disponíveis no ambiente colaborativo 2D (Quadro Branco Compartilhado).

Nesta etapa também foi criado um wiki para o desenvolvimento da proposta urbanística de cada grupo, e dois fóruns de discussão: um para discussão de características da área em estudo e sua situação de implantação, e o outro para a discussão do tema do projeto da disciplina levando em conta agora a área escolhida para o projeto. Cada grupo também deveria analisar a proposta urbanística de outro grupo e colocar a análise neste fórum para discussão, entretanto apenas um grupo colocou a análise no fórum.

$\mathrm{Na}$ terceira etapa, cada aluno desenvolveu um modelo tridimensional da sua proposta arquitetônica. Estes modelos foram inseridos no terreno com entorno modelado anteriormente e foram gerados arquivos VRML a partir de cada proposta, estes ambientes ficaram disponíveis no ambiente colaborativo 3D, um desses ambientes pode ser visto na FIG. 4. Todos os estudantes podiam entrar nas propostas dos demais e circular simultaneamente enquanto conversavam no bate-papo.

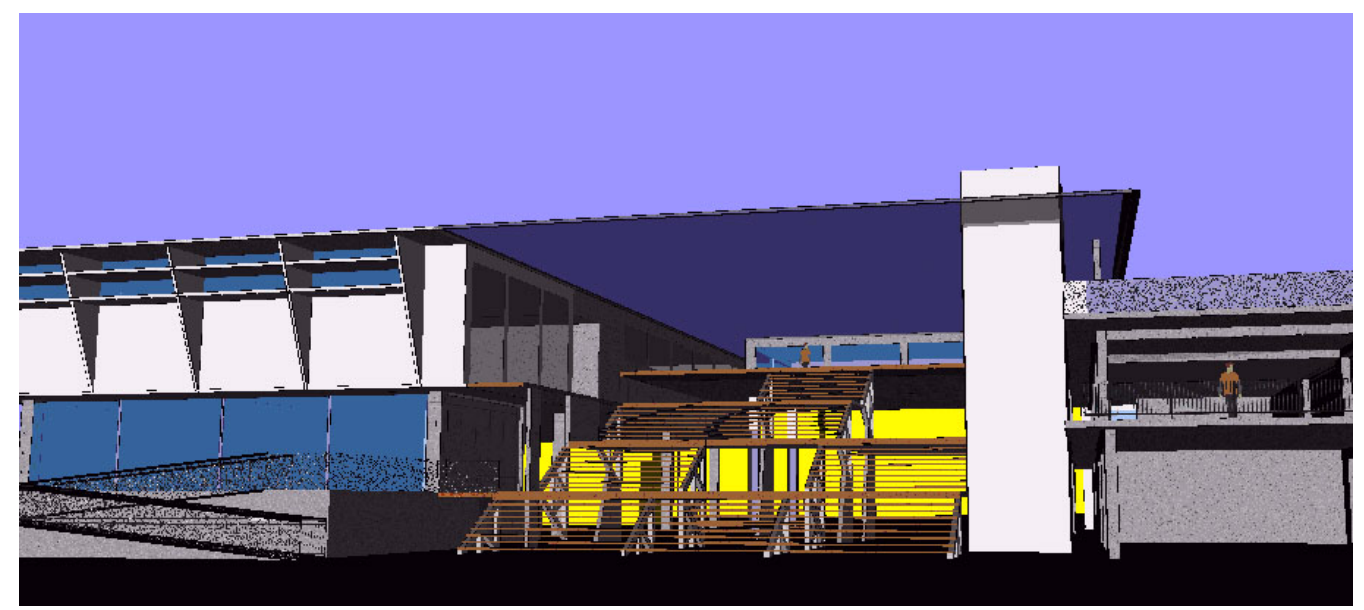

FIGURA 4: Ambiente colaborativo 3D - Proposta de um estudante inserido no terreno.

A proposta deste exercício era de que os modelos fossem sendo atualizados no ambiente colaborativo 3D à medida que o projeto fosse se desenvolvendo, entretanto apenas $15 \%$ dos estudantes (dois estudantes) atualizaram seus modelos ao longo do desenvolvimento do projeto, a maioria colocou apenas o modelo da proposta final.

Ao final do semestre os estudantes responderam um questionário referente ao uso do AVA-AD na disciplina de Projeto Arquitetônico III, foi feita, também, uma entrevista com a professora responsável pela disciplina. 


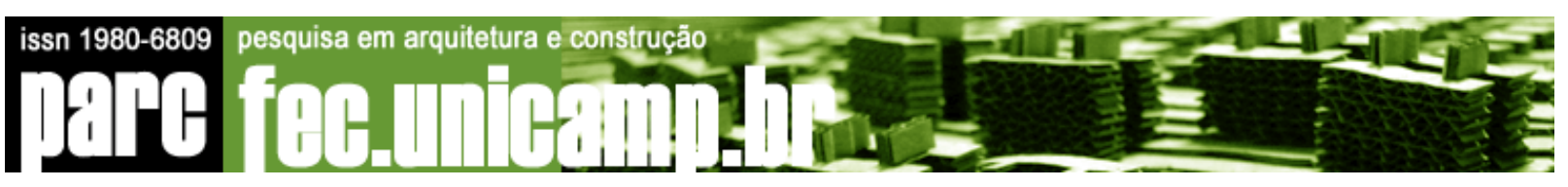

\section{Resultados}

Chegou-se a estes resultados levando em conta as respostas dos estudantes ao questionário aplicado ao final do semestre, a entrevista feita com a professora da disciplina ao final do semestre além de todo o material que ficou armazenado no AVA-AD e observação e conversa com os participantes ao longo do semestre. Observa-se que dos 13 estudantes matriculados na disciplina, 10 responderam o questionário aplicado ao final do semestre. A análise foi dividida em duas categorias:

- Quanto à participação - nesta parte é considerada a participação no ambiente e o que pode ter estimulado ou desestimulado a participação considerando que o uso do AVA-AD não era obrigatório para os estudantes.

- Quanto à contribuição do AVA-AD nas soluções do projeto arquitetônico - nesta parte são considerados os resultados finais de projeto alcançados pelos estudantes e em que aspectos o uso do ambiente pode contribuir no desenvolvimento do projeto arquitetônico.

\section{Resultados referentes à participação dos estudantes}

Quanto à participação geral no AVA-AD observou-se que $46 \%$ dos estudantes (seis estudantes) participaram de menos de 50\% das atividades propostas, 38\% (cinco estudantes) participaram de $50 \%$ a $70 \%$ das atividades e apenas $16 \%$ dos estudantes (dois estudantes) participaram de mais de $70 \%$ das atividades conforme mostra o GRAF. 1 . Observa-se que $54 \%$ dos estudantes (sete estudantes) participaram de mais de 50\% das atividades propostas.

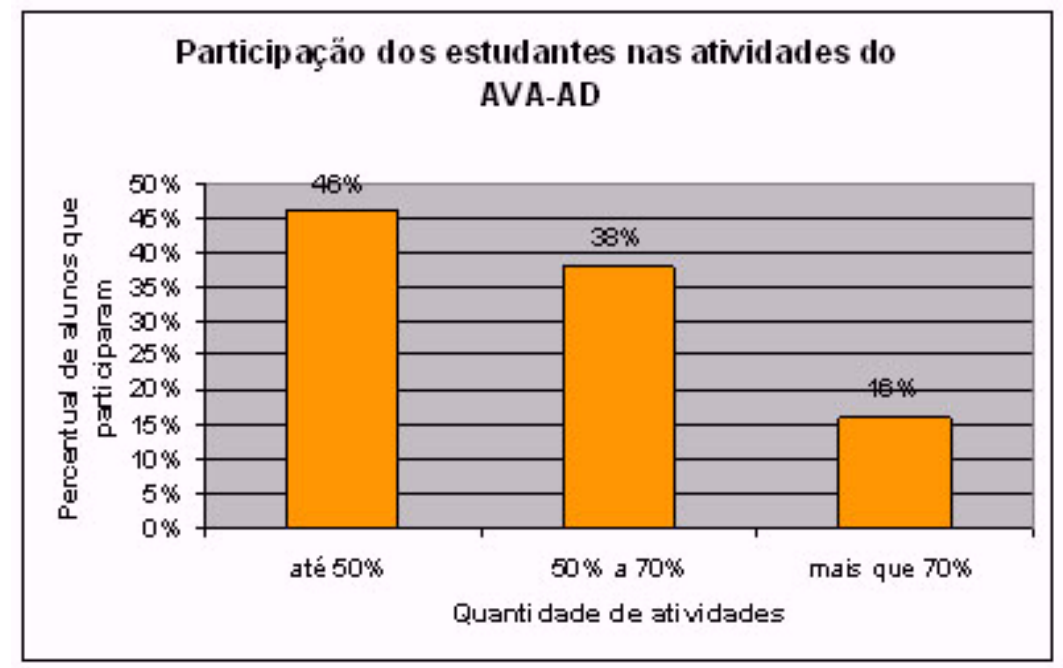

GRÁFICO 1: Participação dos estudantes nas atividades do AVA-AD. 
Dentre os principais pontos identificados destaca-se a dificuldade para inserção de material gráfico nos ambientes colaborativos 2D e 3D, em função da necessidade de primeiramente o material ter de ser enviado para o administrador do ambiente para que este possa disponibilizar online. Esta limitação fez com que os estudantes se sentissem desestimulados para o desenvolvimento de atividades colaborativas nestes dois ambientes, pois muitas vezes quando as representações gráficas e modelos tridimensionais por eles elaborados eram disponibilizadas pelo administrador, os estudantes já haviam avançado em suas propostas, ficando o material do ambiente desatualizado. A experimentação desenvolvida apontou para a necessidade de viabilizar a inserção de imagens e modelos tridimensionais pelos próprios estudantes nestes dois ambientes colaborativos, permitindo desta forma que os grupos de estudantes possam interagir e construir propostas online a partir do uso destas ferramentas.

Outro aspecto em que fica evidenciada a necessidade de alteração é no processo de inserção de imagens em atividades do editor de texto compartilhado, pois apesar de ser possível colocar imagens nos wikis (editor de texto compartilhado), o processo disponível para os estudantes estava muito longo. Enquanto que para os professores a inserção de uma imagem no wiki se resumia em clicar no comando "inserir imagem" e escolher a imagem, para os alunos era preciso colocar a imagem no seu espaço de documentos, copiar o URL com que a imagem ficava neste espaço e usar este URL na janela de "inserir imagem". Era preciso ainda, compartilhar a imagem com todos, no espaço de documentos, para que todos pudessem ver a imagem no wiki. Em função das características da disciplina de Projeto Arquitetônico, na qual é fundamental o trabalho com imagens, indica-se a necessidade de alteração no processo disponibilizado para os estudantes na ferramenta editor de texto compartilhado buscando tornar ágil o processo.

O estudo aponta, ainda, para a necessidade de aperfeiçoamento da interface do AVA$A D$ de maneira a permitir que o estudante atualize o seu espaço de trabalho identificando as atividades já analisadas, em andamento ou concluídas, visto que a maioria dos estudantes apontou ter tido dificuldade em visualizar quais tarefas já havia concluído devido à possibilidade de se chegar a uma mesma tarefa por diversos caminhos.

O estudo identificou, também, aspectos positivos do uso do AVA-AD na disciplina de Projeto Arquitetônico III, situações em que ferramentas utilizadas foram consideradas de efetivo apoio ao desenvolvimento da disciplina. Destaca-se a possibilidade de Visualização 


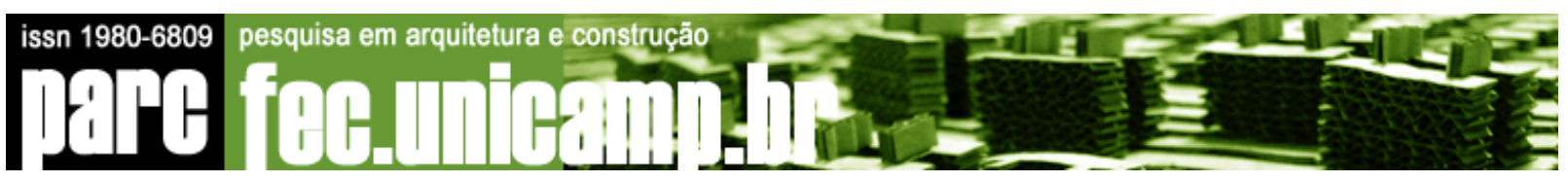

do andamento da disciplina, pois através da página inicial da disciplina no AVA-AD era possível ver toda a programação da disciplina, data de entrega dos trabalhos, discussões em andamento bem como o que havia sido feito em todas as semanas até o momento.

Outro aspecto a destacar como apoio efetivo das ferramentas do ambiente foi 0 armazenamento e troca de documentos entre os participantes. Cada participante do curso tinha um espaço para armazenamento de arquivos os quais podiam ser compartilhados com qualquer outro participante facilitando a troca de documentos.

A visualização de trabalhos também foi apontada como um dos principais aspectos positivos, pois os trabalhos de todos os grupos e mesmo os individuais ficavam disponíveis no AVA-AD, o que facilitava o acesso dos estudantes e docentes ao material produzido.

O GRAF. 2 demonstra os aspectos apontados pelos estudantes como àqueles que contribuíram para a disciplina de Projeto arquitetônico III.

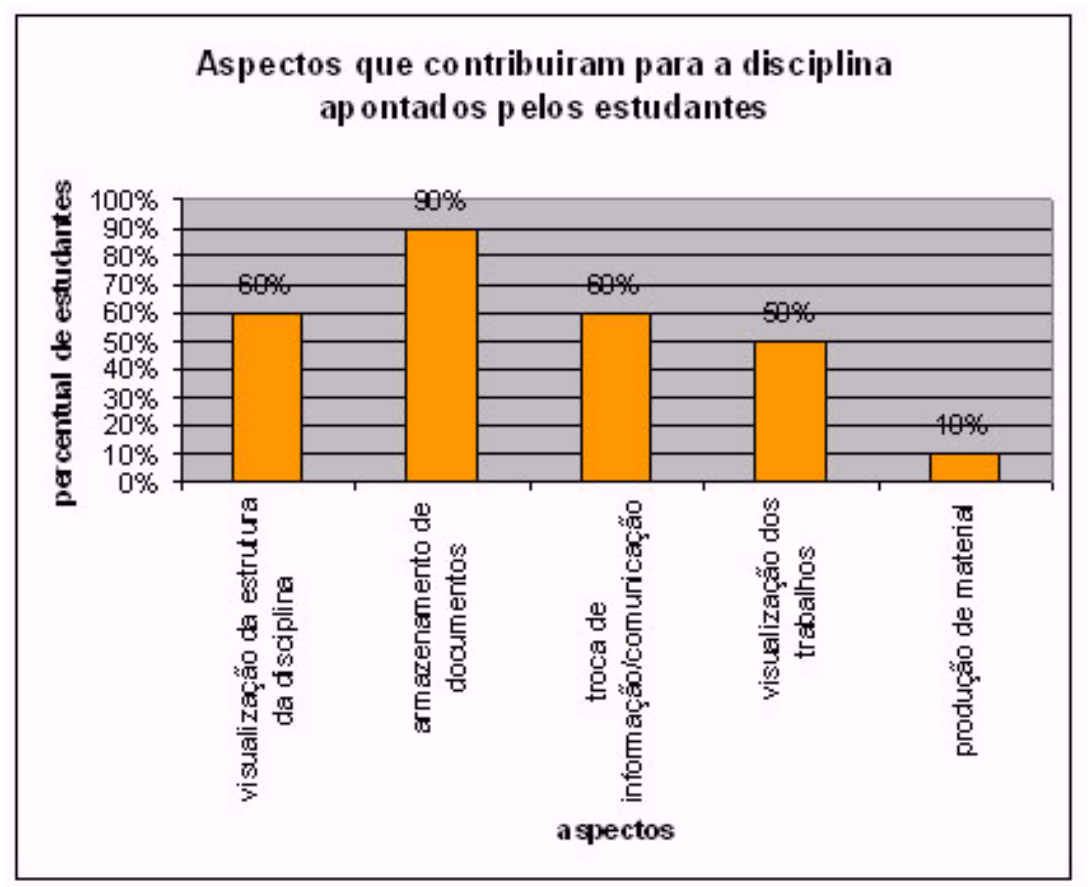

GRÁFICO 2: Aspectos que contribuíram para a disciplina apontados pelos estudantes.

Estudos de inclusão de tecnologia no ensino de graduação, como o proposto nesta pesquisa, devem levar em consideração também os problemas relacionados ao acesso a computadores e principalmente a internet, alguns estudantes só tinham este acesso na universidade. No entanto, como a utilização do ambiente foi proposta como um apoio a 


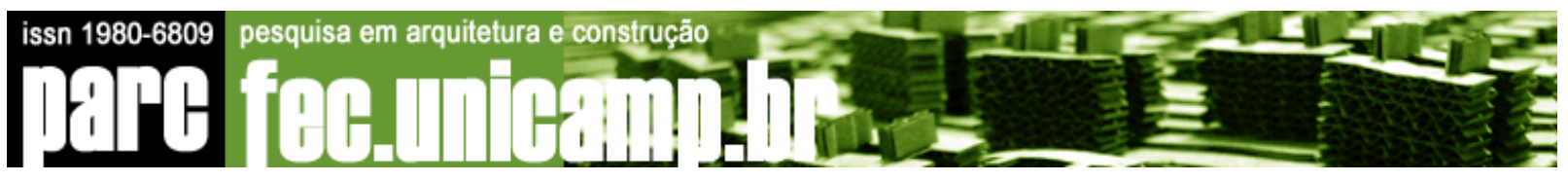

disciplina, este percentual não impediu de se utilizar o AVA-AD para dar este apoio, porém foi possível perceber a participação mais constante no ambiente dos estudantes que tinham acesso mais fácil à internet.

\section{Resultados referentes à contribuição do AVA-AD nas soluções do projeto arquitetônico}

Foi destacado pela professora responsável pela disciplina de Projeto Arquitetônico III que o projeto final desenvolvido pelos alunos que participaram mais ativamente no AVA-AD, 23\% dos estudantes (três estudantes), foi melhor que o projeto dos estudantes que não participaram. Na sua avaliação a solução de projeto por eles apresentada foi em um nível bastante superior das demais, ela salienta que estes estudantes conseguiram explorar mais opções e aprofundar melhor a proposta. A maquete eletrônica da proposta final de um destes estudantes pode ser vista na FIG. 5.

A professora da disciplina comenta, também, que outros estudantes apresentaram boas soluções, mas não conseguiram alcançar o mesmo grau de aprofundamento. Outro destaque feito por ela foi o caso de algumas alunas que tinham muita dificuldade em usar o computador ao início da proposta, mas depois de superada esta dificuldade sentiram a evolução do próprio trabalho.

A seguir são apresentadas considerações quanto a que aspectos do uso do AVA-AD podem ter contribuído no desenvolvimento de projeto arquitetônico levando a este resultado.

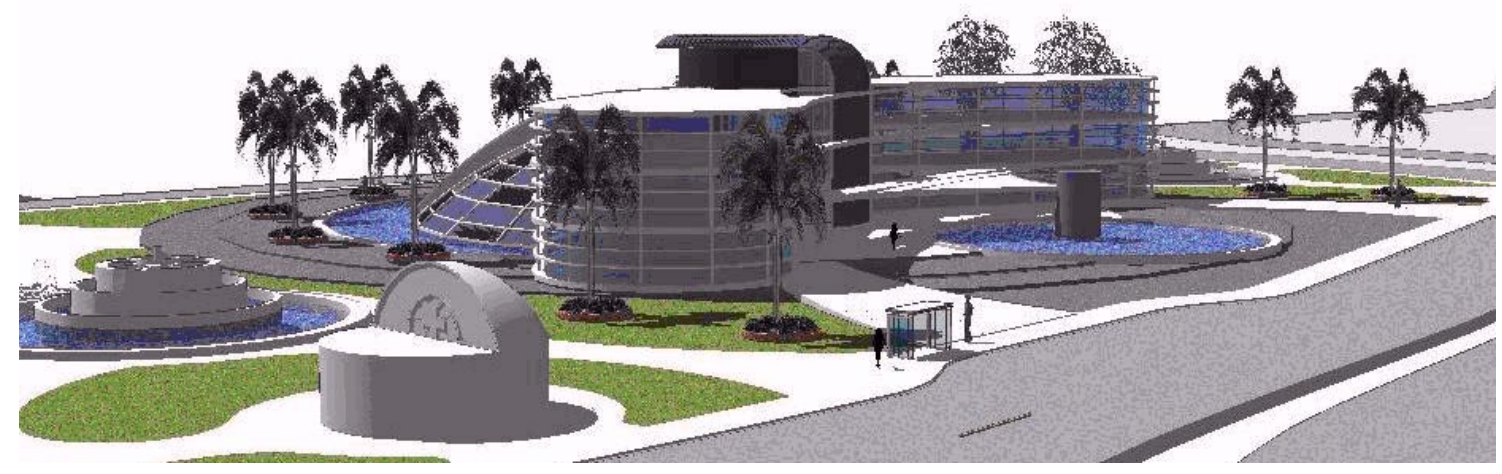

FIGURA 5: Vista da maquete eletrônica da proposta de um dos estudantes. 


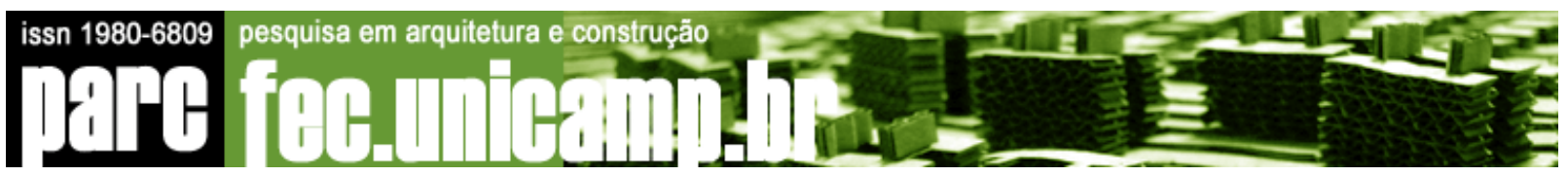

Uma consideração importante é a possibilidade de visualização tridimensional através do ambiente que, diferente de uma maquete física, permite percorrer o ambiente que se está projetando como se o observador estivesse dentro dele, circulando e, controlando os pontos de vista em tempo real. Conforme colocam Fernandéz e Piegari (2005) estas técnicas informáticas aproximam a apreensão do espaço à dimensão que se percebe percorrendo o espaço. Apesar de não ser igual a percorrer um espaço já construído, real, a possibilidade de controlar os pontos de vista em tempo real e circular pela maquete eletrônica se aproxima mais dessa dimensão do que observar uma maquete de fora.

Outro aspecto que pode ter contribuído para que os estudantes que participaram mais ativamente do AVA-AD chegassem a uma solução de projeto melhor é o fator apontado por Palloff e Pratt (2002) quanto à possibilidade de pensar mais nas discussões através dos fóruns assíncronos, permitindo responder a um fórum no tempo que desejar o estudante pode pensar mais no que está fazendo o que possibilita aprofundar mais do que numa discussão ao vivo.

\section{Considerações Finais}

Neste trabalho foram estudados o processo desenvolvimento e ensino de projeto arquitetônico, a inserção da computação gráfica e de ambientes virtuais de aprendizagem no processo de desenvolvimento do projeto arquitetônico. O Ambiente Virtual de Aprendizagem em Arquitetura e Design (AVA-AD) foi testado na disciplina de Projeto Arquitetônico III ao longo do primeiro semestre de 2007 com o objetivo de apontar pontos positivos e pontos que precisam ser melhorados no ambiente para dar apoio especificamente às disciplinas de projeto arquitetônico.

Considera-se que o uso da computação gráfica através do AVA-AD seja essencial para este ambiente dar apoio às disciplinas de Projeto Arquitetônico devido ao uso intenso da linguagem gráfico-visual nestas disciplinas. Considera-se que o uso mais intenso e específico da computação gráfica no AVA-AD se dê através dos ambientes colaborativos 2D e 3D. O ambiente colaborativo 2D permite a colaboração dos participantes de forma bidimensional e o ambiente colaborativo 3D se apresenta como uma ferramenta principalmente de visualização do espaço tridimensional. Entretanto esta visualização é de extrema importância, pois permite aos usuários imergirem no ambiente visualizado e controlar os pontos de vista em tempo real como se estivessem andando pelo ambiente o que permite ter uma apreensão diferenciada 


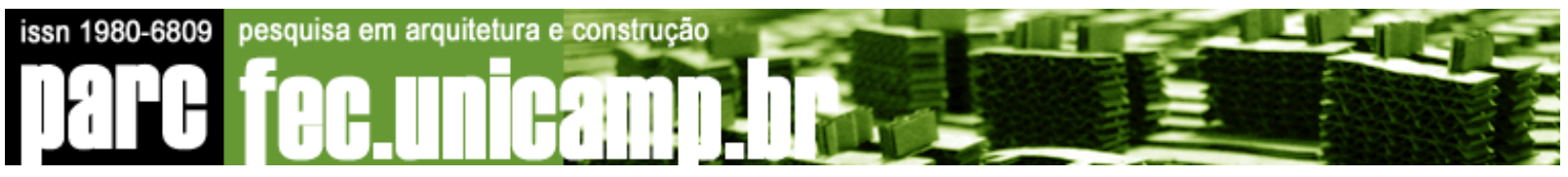

do espaço, mais próxima do real. Ambos os ambientes apresentam um grande potencial de interação entre os participantes da disciplina permitindo que certas questões do projeto sejam resolvidas rapidamente, tanto entre colegas de um mesmo grupo como dúvidas com o professor, sem precisar esperar até a próxima aula presencial deixando mais tempo disponível nestas aulas para apresentação de novos tópicos e conceitos, orientações e encaminhamentos bem como a ampliação e aprofundamento das discussões.

Ao longo do semestre foram encontradas diversas dificuldades para o efetivo uso do ambiente e também dificuldades relacionadas ao acesso dos estudantes a computadores e, principalmente, à internet. Considera-se, entretanto, que o uso do AVA-AD na disciplina de Projeto Arquitetônico III atingiu o objetivo de dar suporte ao ensino de projeto arquitetônico, principalmente facilitando a comunicação e troca de informação fora do horário de aula.

\section{Referências}

DEL RIO, Vicente. Projeto de arquitetura: entre criatividade e método. In: Arquitetura: pesquisa \& projeto. Rio de Janeiro: FAU UFRJ, 1998.

FERNÁNDEZ, Mônica; PIEGARI, Ricardo. Representação digital da arquitetura. 2006.

Disponível em: <http://add.unizar.es/SCRIPT/T-GAME2/scripts/serve_home> Acesso em: 01 outubro 2006.

GONÇALVES, Berenice; PEREIRA, Alice. Resultados do curso on-line "cor no design gráfico". In: GRAPHICA 2005 - VI International Conference on Graphics Engineering for Arts and Design e XVII Simpósio Nacional de Geometria Descritiva e Desenho Técnico. Recife: FASA e ABEG, 2005. Disponível em: <http://www.avaad.ufsc.br> Acesso em: 04 julho 2007. PALLOFF, Renan M.; PRATT, Keith. Construindo comunidades de aprendizagem no ciberespaço: estratégias eficientes para salas de aula on-line. Porto Alegre: Artmed, 2002.

PEREIRA, Alice Cybis. O que é o AVA-AD. Disponível em: <http://www.avaad.ufsc.br> Acesso em: 04 julho 2007.

SCHLEMMER, Eliane. Metodologias para educação a distância no contexto da formação de comunidades virtuais de aprendizagem. In: Ambientes virtuais de aprendizagem. Porto Alegre: Artmed, 2005.

SCHÖN, Donald. Educando o profissional reflexivo: um novo design para o ensino e a aprendizagem. Porto Alegre: Artmed, 2000. 